\title{
A CONCEPÇÃO DE DESENVOLVIMENTO SUSTENTÁVEL (DS) SOB UMA PERSPECTIVA CRÍTICA
}

\author{
Gabriela Lopes Cirelli ${ }^{1}$
}

\section{RESUMO}

O presente artigo tem por escopo analisar o conceito de DS e críticas existentes à sua utilização meramente retórica. Para tanto, será realizado o estudo de sua origem e seus desdobramentos, bem como a necessidade de seu aprimoramento até se chegar ao que se convencionou denominar de ideal de "sustentabilidade". Desse modo, serão tecidos alguns comentários acerca das perspectivas atinentes aos conceitos de "desenvolvimento como liberdade" e "desenvolvimento includente", além das três correntes qualificativas para o desenvolvimento ambiental. O método de pesquisa adotado é o dedutivo, com análise de livros, periódicos e artigos acerca do tema.

Palavras-chave: Meio Ambiente; Desenvolvimento econômico; Equilíbrio; Desenvolvimento sustentável; Sustentabilidade

\section{THE CONCEPTION OF SUSTAINABLE DEVELOPMENT (SD) UNDER A CRITICAL PERSPECTIVE}

\begin{abstract}
The purpose of this article is to analyze the concept of SD and the existing criticisms of its merely rhetorical use. For this purpose, the study of its origin and consequences, as well as the need for its improvement until reaching what is conventionally called the "sustainability" ideal. Thus, some comments will be made about the perspectives related to the concepts of "development such as freedom" and "inclusive development", in addition to the three qualifying currents for environmental development. The research method adopted is the deductive, with analysis of books, periodicals and articles on the subject.
\end{abstract}

Keywords: Environment; Economic development; Balance; Sustainable development; Sustainability

\section{INTRODUÇÃO}

Com o passar dos anos, tornou-se cada vez mais urgente analisar a relação do ser humano com a natureza sob uma ótica sustentável: a busca pela coexistência harmônica entre proteção ambiental e desenvolvimento econômico é, há um certo tempo, tema objeto de amplo debate mundial.

\footnotetext{
${ }^{1}$ Mestre em Ciência Jurídica pela Universidade Estadual do Norte do Paraná (UENP). Professora CRES de Direito Processual Civil na UENP, Centro de Ciências Sociais Aplicadas, Campus de Jacarezinho. Procuradora da Câmara Municipal de Cambará-PR. E-mail: gabriela.cirelli@ uenp.edu.br
}

Rev. de Direito e Sustentabilidade | e-ISSN: 2525-9687 | Evento Virtual | v. 6 | n. 1 | p. 37-54 | 
Cuida-se justamente da necessidade de se conciliar duas situações aparentemente antagônicas: de um lado, o incentivo do desenvolvimento socioeconômico e, de outro, a proteção ambiental, que se torna possível com a utilização racional dos recursos naturais, sem que isso cause danos ambientais e o esgotamento dos recursos naturais não renováveis.

Nesse diapasão, serão trazidos à tona, no presente artigo, os preceitos básicos do conceito de desenvolvimento sustentável e, por via de corolário, algumas críticas a essa concepção e sua distinção com o ideal de sustentabilidade; isso porque, dentre outros fatores, sob a ótica do desenvolvimento sustentável, como decorrência do próprio termo, em primeiro lugar se preocupa em "desenvolver" para apenas depois "sustentar", ou seja, para somente após se preocupar com a higidez ambiental.

Nesse contexto, almeja-se delinear e distinguir tais conceitos para, com isso, entender qual deles se presta, efetivamente, a cuidar do bem ambiental, apresentando-se duas ideias a respeito das perspectivas atinentes aos conceitos de desenvolvimento como liberdade e desenvolvimento includente. Ademais, serão objeto de menção alguns aspectos acerca de três correntes qualificativas para o desenvolvimento ambiental: a liberal, a culturalista e a ecossocialista. Destarte, a intenção é extrair o que há de positivo na corrente do ecossocialismo, que é justamente o escopo de refutar o modo de acumulação capitalista/moderna.

Como método, será utilizado o dedutivo, com pesquisa em artigos, periódicos, monografias e livros.

\section{Desenvolvimento sustentável (DS): conceito e evolução}

Em primeiro lugar, cumpre assinalar que o tema ambiente - enquanto uma vertente a ser considerada na discussão pelo desenvolvimento - ocupou o debate científico e social apenas no século XX (PADILHA, 2010, p. 243). Na década de 1960, houve uma repercussão significativa do livro Primavera Silenciosa (1962), de Rachel Carson - a bióloga norteamericana que alertava sobre os efeitos cancerígenos do DDT - que iniciou o importante debate envolvendo as relações entre economia, desenvolvimento e ambiente.

Com o grande evento internacional consagrado como o marco histórico da origem do Direito Internacional do Meio Ambiente, a Conferência das Nações Unidas sobre o Meio Ambiente Humano, em Estocolmo, Suécia (1972), lançou-se o embrião para a construção da 
terminologia desenvolvimento sustentável, repetida nas demais conferências sobre o ambiente, em especial na Eco-92.

Ocorre que, originalmente (em 1973), Maurice Strong e Ignacy Sachs formularam o conceito de ecodesenvolvimento, com a intenção de gerar novos modos de produção, e talvez novos estilos de vida, de reconhecer as condições e as potencialidades ecológicas regionais, cujo escopo era identificar, reconhecer e respeitar a diversidade ética, além de restabelecer a autoconfiança das comunidades para a gestão participativa dos recursos naturais (MAIA, 2015).

Além disso, o aludido conceito - bastante significativo do ponto de vista da problemática ambiental - estava baseado nas ideias de justiça social, eficiência econômica, condicionalidade ecológica e respeito à diversidade cultural; todavia, tal ideia foi rejeitada por ter sido posta dentro de uma linha de pesquisa e ação mais social. Desse modo, no intuito de substituí-lo, surgiu o conceito de desenvolvimento sustentável, contrapondo-se a ele do ponto de vista das condicionantes ecológicas próprias do ambiente, e para priorizar as questões sociais em relação às econômicas, proposto e divulgado dentro de grandes agências internacionais (MAIA, 2015).

Assim, Padilha (2010, p. 243) assinala que coube à Assembleia Geral da ONU, em 1983, determinar a criação de uma comissão especial para o estudo do tema, dada a preocupação crescente com as tendências do desenvolvimento econômico e populacional e suas consequências em relação ao ambiente global, indicando, para a sua presidência, Gro Harlem Brundtland, então primeira ministra da Noruega que - após anos de estudos, análises e debates em todo o mundo, em 1987, a Comissão Mundial sobre Meio Ambiente e Desenvolvimento produziu um relatório intitulado Brundtland - "Nosso Futuro Comum", cuja proposta consiste na promoção do desenvolvimento sustentável (DS), uma categoria do desenvolvimento que se ocupa em equacionar a exploração do ambiente para as satisfações e necessidades da geração presente, sem que essa exploração comprometa o igual direito das gerações futuras.

O conceito em questão somente se consagrou, de forma efetiva, na Conferência das Nações Unidas sobre o Meio Ambiente e Desenvolvimento, a Rio/92, introduzido no Direito Internacional do Meio Ambiente pelo "Relatório Brundtland", considerando que o ambiente deve ser parte integrante do processo de desenvolvimento, estando expresso em vários dos 27 princípios da Declaração de Princípios (PADILHA, 2010, p. 245). 
De acordo com o aludido Relatório, considera-se o desenvolvimento sustentável como aquele "[...] que satisfaz as necessidades presentes, sem comprometer a capacidade das gerações futuras de suprir suas próprias necessidades”. Assevera Maia (2015) que o relatório em questão também expõe que o desenvolvimento sustentável deve promover o crescimento de forma a acabar com a pobreza, revelando-se justo e equitativo, de maneira a viabilizar o uso do patrimônio ambiental de forma menos intensiva. De igual modo, evidencia que é preciso atender as necessidades humanas essenciais, a saber: alimentação, saneamento, água, além do emprego e a reorientação da tecnologia, administrar riscos e incluir ambiente e economia nos processos decisórios.

Cumpre destacar que o relatório em comento, segundo Padilha (2010, p. 244), apresenta uma perspectiva nova na discussão que envolve o embate entre desenvolvimento e ambiente, apresentando uma proposta de desenvolvimento sustentável, sobre a qual os autores têm debatido para desenvolver uma definição do que esse conceito vem a ser, enquanto um desafio para a humanidade, haja vista a herança de degradação ambiental dos recursos naturais do planeta, explorados de forma extremamente agressiva e devastadora, resultando na poluição da água, do ar, do solo, na extinção de espécies e de um acúmulo insuportável de resíduos tóxicos. Por outro lado, a mesma autora menciona a aceleração do ritmo de produção geradora de acumulação de riquezas, conhecimento científico e grande expansão do consumo não eliminaram, mas (em verdade) acirraram ainda mais o processo de empobrecimento da população mundial, com aumento considerável do índice de pobreza extrema.

A preocupação com o não esgotamento dos recursos naturais do planeta - segundo Padilha (2010, p. 245) - é uma garantia da própria continuidade da vida, em todas as suas formas, que não pode estar submetida, tão livremente, às leis do mercado econômico, razão por que se exige a adoção de um novo modelo de desenvolvimento econômico por meio da imposição de limites à exploração desenfreada e degradatória dos recursos naturais do planeta, que - em benefício de poucos - coloca em risco a sobrevivência de todos.

Nesses termos, desenvolvimento sustentável (DS) é uma locução verbal na qual se ligam dois conceitos, de modo que "sustentabilidade" passa a qualificar ou caracterizar o “desenvolvimento". Significa dizer que a harmonização dos interesses em jogo não pode ser feita ao preço da desvalorização do ambiente ou da desconsideração de fatores que possibilitam o equilíbrio ambiental (MACHADO, 2013).

Por não serem os recursos naturais inesgotáveis, torna-se inadmissível que as 
atividades econômicas se desenvolvam alheias a esse fato; exige-se, assim, a coexistência harmônica entre economia e ambiente, a fim de coibir o esgotamento dos recursos naturais aos quais se tem acesso hoje, tolhendo o direito de seu usufruto pelas gerações futuras.

Com efeito, Padilha (2010, p. 246) enfatiza que o compromisso de sustentabilidade ambiental - albergado pela CF/88 - está representado na adoção constitucional de um modelo de desenvolvimento econômico que leve em conta a vertente da proteção ambiental, ou seja, que concilie o desenvolvimento com o respeito à proteção ambiental, conforme o disposto no Título VII do Texto Constitucional, sobre a ordem econômica, que inclui - entre os princípios gerais da atividade econômica - a defesa do ambiente, inclusive mediante tratamento diferenciado.

Nesses termos, Padilha (2010, p. 247) sustenta que a CF/88 - enquanto carta constitucional democrática aberta a valores da comunidade, nem sempre harmônicos entre si adota a proteção e equilíbrio do ambiente como um direito. Por outro lado, um modelo econômico de produção que - apesar de ter como base a livre iniciativa e apropriação privada de bens, parâmetros essenciais do sistema capitalista de produção - exige que o referido modelo respeite a defesa do ambiente, levando em consideração os impactos ambientais específicos, o que nada mais é que a proposta do desenvolvimento sustentável.

Há - inegavelmente - uma tensão dialética permanente entre a proteção ambiental e o desenvolvimento econômico, o que exigiu o surgimento de um princípio que tentasse atenuar esse conflito, haja vista a importância de um ambiente equilibrado para a permanência da vida no planeta Terra; assim, a defesa do ambiente se trata de medida de rigor e que deve ser objeto de preocupação do Poder Público:

A defesa do meio ambiente é uma dessas questões que obrigatoriamente deve constar da agenda econômica pública e privada. A defesa do meio ambiente não é uma questão de gosto, de ideologia e de moda, mas um fator que a Carta Maior manda levar em conta (MACHADO, 2003, p. 32).

Conforme preceitua Machado (2013, p. 90), em que pese a CF/88 não utilize a expressão "desenvolvimento sustentável", no momento em que insere o dever de defender e preservar o ambiente para as presentes e futuras gerações, acaba por representar a essência do princípio da sustentabilidade, tratando-se, pois, de um princípio implícito. Extrai-se do referido dispositivo que os recursos ambientais não são inesgotáveis, tornando-se inadmissível que as atividades econômicas se desenvolvam alheias a esse fato. Nota-se, assim, 
que a legislação brasileira acompanhou a agenda internacional acerca do paradigma da sustentabilidade e a inseriu como vetor para a construção de uma nova ética a ser experimentada pela civilização contemporânea.

O citado conceito de DS inevitavelmente comporta traços éticos, os quais fundamentam uma crítica à forma pela qual o progresso técnico no século XX se desenvolveu (CAMPOS JUNIOR, 2012, p. 222); consiste, assim, em um dever ético de compreensão das liberdades, em correspondência com o valor expresso pelo princípio da dignidade humana. Nesses termos, atitude ética sustentável é, pois, aquela em cuja ação se considere o desenvolvimento como bem-estar atemporal, isto é, um bem para a geração presente e as futuras (Ibidem, p. 226).

Para Gadotti (1999, p. 42), o “desenvolvimento sustentável deve ser economicamente factível, ecologicamente apropriado, socialmente justo e culturalmente equitativo, sem discriminação". Para Sampaio (2003, p. 53), as presentes gerações não podem deixar para as futuras gerações uma herança de déficits ambientais ou do estoque de recursos e benefícios inferiores aos que receberam das gerações passadas. Esse é um princípio de justiça ou equidade que nos obriga a simular um diálogo com nossos filhos e netos na hora de tomar uma decisão que lhes possa prejudicar seriamente.

Para o atendimento do que se tem por desenvolvimento sustentável na sociedade atual, verifica-se a necessidade de tratar o meio ambiente não mais por meio de gerenciamento de riscos - método utilizado na globalização para sustentar o modelo capitalista -, mas mediante a identificação, criação e incentivo de mecanismos capazes de relacionar os interesses do desenvolvimento econômico e ambiental na busca de uma justiça social e responsável para com as gerações futuras, a partir da atuação conjunta de todos os atores sociais (JAQUES; SILVEIRA, 2019, p. 174).

Ante o exposto, passa-se a explicitar, no próximo item, alguns aspectos críticos sobre uma possível distorção que pode ocorrer com o referido princípio.

\section{O DS sob um viés crítico: a necessidade de se caminhar para a efetiva busca do ideal de sustentabilidade}

Apesar da inegável relevância do princípio em comento, ocorre que - não raro - o desenvolvimento sustentável tem sido objeto de apropriação corporativo-empresarial, já que 
utilizado a serviço da economia ambiental. E, afinal, o que se pode entender por economia ambiental? Segundo Tybusch (2011, p. 71), ela propõe o desenvolvimento de mecanismos que objetivem a alocação eficiente dos recursos naturais, utilizando-se de métodos de valoração e a tentativa de "criação" de mercados para os bens ambientais. Justamente por isso, tem sido alvo de severas críticas, uma vez que partem da observação acerca do conceito de "externalidades", o que reduz a real dimensão do dano ambiental, que não é visto como um problema, mas como decorrência de uma operação econômica.

Iniciada na década de 1970 como desmembramento da ciência econômica, a economia ambiental se associaria de forma direta ao conceito de desenvolvimento sustentável, eis que algumas áreas de atuação importantes desse estudo estão representadas pela avaliação e monetarização de bens e danos ambientais, contabilidade ambiental, estatística ambiental e pesquisa ambiental. O questionamento a ser enfrentado, entretanto, instaura-se em observar se é possível alcançar novas formas de desenvolvimento no capitalismo global em rede. Uma primeira análise cuida da dificuldade em superar as contradições fundamentais do sistema capitalista, principalmente no que diz respeito à tendência em se apropriar do ambiente de forma degenerativa. Os interesses do sistema econômico, portanto, acabam prejudicando o objetivo de abrangência intergeracional, o alcance da justiça e equidade sociais, bem como a proteção ecológica propriamente dita (TYBUSCH, 2011, p. 82).

Já a corrente de economia ecológica, na lição de Tybusch (2011, p. 83) busca analisar as trocas físicas de energias e materiais e percebe a impossibilidade, ou a dificuldade metodológica em se atribuir valor de forma correta aos bens e serviços ambientais. Enfatizase, assim, o aspecto econômico da questão ambiental, mas sem perder de vista a dimensão social; ocorre que o capitalismo trabalha com os custos ambientais, trabalhistas, econômicos e social, em que se verifica uma tensão dialética entre capital e natureza, que pode alternar períodos benéficos para ambos os pontos de conflito (capital e natureza) e, ao mesmo tempo, gerar restrições para cada um deles dependendo da situação atual do mercado. Salienta-se, principalmente, a necessidade de impor limitações ambientais ao crescimento econômico e à expansão do capitalismo.

Em virtude disso é que o conceito de DS pode ser apropriado por diversos atores e grupos de interesse, em que cada um deles leva em consideração apenas a dimensão mais conveniente para a sua organização. Nesse viés, Tybusch (2011, p. 87) menciona que um dos claros exemplos que se pode delinear é referente ao sistema econômico, mais especificamente 
ao segmento empresarial que se apropria do conceito, reduzindo a questão ambiental à perspectiva do ambiente material tão somente. Por consequência, desconsidera as identidades culturais, as singularidades "e a autonomia diante da obrigatoriedade imposta por uma globalização dominadora" (LEFF apud TYBUSCH, 2011, p. 87).

Desse modo, é possível observar que o conceito de DS acaba se configurando como “uma posição programática, um metarrelato² com características utópicas que estabeleçam um campo discursivo comum, possibilitando alianças entre ambientalistas e agentes sociais interessados em crescimento econômico" (RIBEIRO apud TYBUSCH, 2011, p. 86). Outra crítica normalmente feita é a de que, sob a ótica do DS, costuma-se primeiro se desenvolver para só depois se verificar como sustentar, o que não parece ser a melhor forma de se buscar o equilíbrio necessário para a convivência de desenvolvimento econômico e proteção ambiental.

De acordo com Sachs (apud TYBUSCH, 2011), o desenvolvimento é um conceito multidimensional, cujos objetivos devem ser sempre sociais e éticos, com uma perspectiva ambiental explicita, ou seja, a possibilidade de fraternidade e solidariedade ao observar as gerações futuras. Na perspectiva do autor, entretanto, o desenvolvimento não pode ser visto em separado do crescimento econômico e, por si só, este não garante aquele, sendo possível evidenciar o mau desenvolvimento quando há apenas crescimento do Produto Interno Bruto (PIB) dos países em desenvolvimento, percebendo-se o aumento do desemprego, pobreza e desigualdades sociais. Cumpre, pois, ao desenvolvimento, a remoção de qualquer estrutura que possa privar as liberdades: "pobreza e tirania, carência de oportunidades econômicas e destituição social sistemática, negligência dos serviços públicos e intolerância ou interferência excessiva de Estados repressivos" (SEN apud TYBUSCH, 2011).

Como propostas capazes de amenizar a desigualdade que o "mau desenvolvimento" pode gerar, de maneira que se busquem objetivos sociais e éticos, tem-se os conceitos de desenvolvimento como liberdade e desenvolvimento includente. No que tange a primeiro conceito, Tybusch (2011, p. 81) pondera que - mesmo com o crescimento econômico global o mundo da atualidade acaba por negar as liberdades fundamentais à maioria das pessoas, as quais são compreendidas como conceito central para a perspectiva do desenvolvimento, pois um dos fatores de avaliação do progresso é, justamente, verificar se houve o aumento das

\footnotetext{
${ }^{2}$ A ideia de metarrelato utópico ambiental tem sua matriz no projeto desenvolvimentista liberal aplicado ao meio ambiente, abrindo espaço para o desdobramento do ambientalismo como uma comunicação genericamente simbolizada na contemporaneidade, resgatando os sonhos do iluminismo, da "razão prática, de racionalidade via de adequação dos meios aos fins últimos (planejamento e tecnologia bem articuladas produzem desenvolvimento sustentável" (RIBEIRO apud TYBUSCH, 2011, p. 86).
} 
liberdades pessoais. Outro fator importante é considerar que o desenvolvimento se vincula, intensa e globalmente, à livre condição de agente das pessoas, em que se constrói, portanto, o conceito de "desenvolvimento como liberdade".

\begin{abstract}
A ligação entre liberdade individual e realização de desenvolvimento social vai muito além da relação constitutiva - por mais importante que ela seja. O que as pessoas conseguem positivamente realizar é influenciado por oportunidades econômicas, liberdades políticas, poderes sociais e por condições habilitadoras como: boa saúde, educação básica e, incentivo e aperfeiçoamento de iniciativas. As disposições institucionais pelo exercício das liberdades das pessoas, mediante a liberdade para participar da escolha social e da tomada de decisões públicas que impelem o progresso dessas oportunidades (SEN apud TYBUSCH, 2011, p. 80).
\end{abstract}

Ainda nesse contexto, Sen (apud TYBUSCH, 2011, p. 80) comenta que a ausência de liberdades substantivas pode ser verificada diretamente com a pobreza econômica, retirando das pessoas a liberdade de se alimentarem, de saciarem a fome, de obterem uma nutrição satisfatória ou o remédio para suas doenças, a carência de saneamento básico ou moradias adequadas. Assim, a privação de liberdade pode se vincular a carência de serviços públicos e assistência social, como a ausência de programas epidemiológicos, de sistemas de assistência médica e de educação.

Existe uma histórica dificuldade metodológica na aplicabilidade do conceito de DS para salvaguarda do ambiente, bem como na formulação de uma técnica jurídico-ambiental capaz de perceber e incorporar - na sua elaboração e aplicação - as diferentes dimensões de sustentabilidade. Faz-se necessário propor um estudo das transformações ecológicas e sua percepção pela técnica-jurídica ambiental em sua direta relação com a composição das singularidades individuais e coletivas ante as modificações na política, técnica e percepções da cena ecológica (problemática ambiental).

O que se verifica, portanto, é uma "configuração idealizada" para o conceito de desenvolvimento. Tybusch (2011, p. 81) admoesta que - em uma perspectiva realista compreende-se que as estratégias de apropriação dos recursos naturais dos países em desenvolvimento e subdesenvolvidos, na perspectiva da globalização econômica, legitimam seus discursos na retórica do desenvolvimento sustentável. Significa dizer, em outras palavras, que o prognóstico é ruim em países com sistemas implementados (ou em implementação) de aceleração do crescimento, de modo que uma política de crescimento sustentável, nos territórios com carência econômica, tende a diluir e perverter o conceito de 
ambiente, burlando com estratégias discursivas as condições de sustentabilidade do processo econômico.

\begin{abstract}
A ideologia do desenvolvimento sostenible desencadeia, assim, um delírio e uma inércia incontrolável de crescimento. O discurso da sostenibilidade aparece como um simulacro que nega os limites do crescimento, para afirmar a corrida desenfreada até a morte entrópica do planeta. $\mathrm{O}$ neoliberalismo ambiental planeja acima de toda lei de conservação e reprodução social para dar curso a processos que ultrapassam toda a norma, referencial e sentido para controla-los. Se as estratégias do ecodesenvolvimento surgiram como resposta à crise ambiental, a retórica da sostenibilidade opera como uma estratégia fatal, uma inércia cega, uma precipitação para a catástrofe (LEFF apud TYBUSCH, 2011, p. 82).
\end{abstract}

Na lição de Tybusch (2011, p. 225), na perspectiva da Ecologia Política, compreende-se que existe uma maior influência do saber e poder econômicos na questão ambiental, ou seja, as práticas discursivas, no que tangem à questão ambiental, partem - na realidade - das políticas públicas, de orientações desenvolvimentistas, resultando em ações que operam a partir de uma lógica de custo e benefício ou de um código-valor para, em um segundo momento, tentar adequá-las na perspectiva da sustentabilidade.

Em termos ambientais, a sustentabilidade é justamente a forma de se colocar em prática a conservação (e não preservação) ambiental, cujo escopo é a conciliação de duas situações aparentemente antagônicas: de um lado, o incentivo do desenvolvimento socioeconômico e, de outro, a proteção ambiental, que se torna possível com a utilização racional dos recursos naturais, sem que isso cause danos ambientais.

Importante distinguir os conceitos de DS e de sustentabilidade: de acordo com Leff (2001, p. 20), enquanto o conceito de DS se apresenta como “parte das estratégias do discurso ambiental neoliberal", o de sustentabilidade estaria mais ligado ao sentido de um constitutivo do ambiente, "como marca da ruptura da racionalidade econômica que negou a natureza e como uma condição para a construção de uma nova racionalidade ambiental". Embora não se trata de entendimento unânime, há quem diga que o DS seria um caminho para se atingir a sustentabilidade:

Sustentabilidade é a capacidade de um sistema humano, natural ou misto resistir ou se adaptar à mudança endógena ou exógena por tempo indeterminado, e, além disso, o desenvolvimento sustentável (DS) é uma via de mudança intencional e melhoria que mantém ou aumenta esse atributo do sistema, ao responder às necessidades da população presente. Numa primeira visão, o DS é o caminho para se alcançar a sustentabilidade, isto é, a sustentabilidade é o objetivo final, de longo prazo (SARTORI et. al., 2014, p. 1). 
Tybusch (2011) alerta que é necessário pensar a questão ambiental para além da perspectiva do desenvolvimento tradicional, haja vista o caráter multidimensional do desenvolvimento, bem como da sustentabilidade, valendo ressaltar que todo processo sustentável tem como fundamento o território como elemento no qual se cristalizam as bases ecológicas e as identidades culturais. Desse modo, o DS não pode ser um conceito padronizado para todos os territórios do globo, já que a padronização econômica desta estrutura conceitual reduz em demasia a perspectiva complexa que envolve o conceito de ambiente. A sustentabilidade envolve também as lutas (BERNA apud TYBUSCH, 2011) nos países em desenvolvimento e subdesenvolvidos por uma percepção de desenvolvimento includente e de desenvolvimento como liberdade.

Nesse ínterim, alude o pensamento de Sachs no sentido de que - não obstante as futuras gerações não contribuam para esta qualidade de vida - para que o progresso social desejado seja possível, cumpre respeitar as "condicionalidades ecológicas, condicionalidades ambientais de outro conceito ético: o conceito ético de solidariedade diacrônica com as gerações futuras" (SACHS, apud MARQUES, 2016, p. 715, tradução nossa).

Dessa forma, a promoção de um desenvolvimento ambientalmente sustentável requer a consideração da necessidade de uma nova posição ética; tendo por premissa que o DS é o caminho para se alcançar a sustentabilidade (o objetivo de longo prazo almejado), resta nítida a suma relevância desse princípio, uma vez que seu escopo maior é preservar a possibilidade de vida no futuro.

Independentemente da forma pela qual essa distinção é feita, insta mencionar que é consenso que há diversas formas de definir DS: conforme lembra Loureiro (2012, p. 55), para alguns, nem conceito propriamente dito é, e sim uma "ideia-força", um conjunto de princípios manifestos em busca de um desenvolvimento qualificado por uma preocupação: “crescer sem comprometer a capacidade de suporte dos ecossistemas e seus ciclos, garantindo a existência social e das outras espécies em longo prazo".

O mencionado autor (2012, p. 56) ainda critica o modelo de DS proposto pela ONU e ratificado pelos governos membros das nações unidas, pois é a mais representativa do ideário das classes dominantes, cabendo, assim, sua problematização e superação. Alude, ainda, que a sustentabilidade se trata de um aspecto mais geral, definindo-o como complexo, instigante e desafiador, já que trouxe um conceito biológico para a política e economia admitindo o contexto ecológico como uma condição objetiva de qualquer atividade social; além disso, 
pensou-se em um desenvolvimento que fosse duradouro, atribuindo-se responsabilidade pela vida das pessoas no futuro a partir do que o cidadão realiza no presente, o que se revela consideravelmente radical em um momento de tanta ênfase no efêmero e imediato (Ibidem, p. 57).

Marques (2016) pondera que o ideal de sustentabilidade há de ser baseado em um conceito de solidariedade - diacrônico e guiado pela "não-reciprocidade" entre as gerações presentes e as futuras - de tal sorte que se permita uma nova concepção de responsabilidade ética que ultrapasse a esfera de proximidade dos sujeitos envolvidos, com verdadeiro vínculo intergeracional.

Esse princípio decorre de uma ponderação que deverá ser feita casuisticamente entre o direito fundamental ao desenvolvimento econômico e o direito à preservação ambiental, à luz do princípio da proporcionalidade, atendendo - a rigor - às necessidades do presente sem comprometer a possibilidade de existência digna das gerações futuras. Para Freitas (2012, p. 41), a sustentabilidade se trata do

[...] princípio constitucional que determina, com eficácia direta e imediata, a responsabilidade do Estado e da sociedade pela concretização solidária do desenvolvimento material e imaterial, socialmente inclusivo, durável e equânime, ambientalmente limpo, inovador, ético e eficiente, no intuito de assegurar, preferencialmente de modo preventivo e precavido, no presente e no futuro, o direito ao bem-estar.

Em termos práticos, o conceito de sustentabilidade, conforme lembra J. Albuquerque (2009, p. 20), está interligado a três noções: uso com racionalidade dos recursos da natureza; respeito à capacidade de suporte (regenerativa) dos ecossistemas e compromisso com as gerações futuras. Importa salientar que o ambiente deve servir de base (fonte de recursos) para o desenvolvimento, devendo ambos conciliar-se e completar-se; assim, Milaré (2009) define sustentabilidade como a qualidade, característica ou requisito do que é sustentável, além de se tratar de um requisito para que os ecossistemas permaneçam iguais a si mesmos, assim como os recursos podem ser utilizados somente com reposição e/ou substituição, evitando-se a sua depleção, de maneira a manter o equilíbrio ecológico, uma relação adequada entre recursos e produção, e entre produção e consumo. Preconiza Milaré (2009, p. 71), ainda, que a ausência da sustentabilidade afeta a própria biodiversidade e atinge a continuação de todas as formas de vida, bem como os valores essenciais do mundo natural.

O desenvolvimento, portanto, não deve ocorrer a todo custo, em virtude de que o 
Planeta Terra não tem uma capacidade ilimitada de suportar a degradação provocada pelo ser humano. O princípio da sustentabilidade, nos moldes do que ensina Leff (2001, p. 31):

[...] surge como uma resposta à fratura da razão modernizadora e como uma
condição para construir uma nova racionalidade produtiva, fundada no potencial
ecológico e em novos sentidos de civilização a partir da diversidade cultural do
gênero humano. Trata-se da reapropriação da natureza e da invenção do mundo; não
só de um mundo no qual caibam muitos mundos, mas de um mundo conformado por
uma diversidade de mundos, abrindo o cerco da ordem econômica-ecológica
globalizada.

Nesse contexto, importa salientar que o tema da sustentabilidade se confronta com o paradigma da "sociedade de risco" de Ulrich Beck, o que implica - segundo Jacobi (2003, p. 192) - a necessária multiplicação das práticas sociais baseadas no fortalecimento do direito ao acesso à informação e à EA em uma perspectiva integradora. Além disso, demanda o aumento de poder das iniciativas baseadas na premissa de que um maior acesso à informação e transparência na administração dos problemas ambientais urbanos pode implicar a reorganização do poder e da autoridade.

Há quem aponte como problemática a defesa acrítica do DS, uma vez que acaba por conservar os lucros e evitar a mudança de hábitos quase sem alterar o rumo (LATOUCHE, 2009); isso porque, conforme já mencionado, muitas vezes, a bandeira desse movimento mascara ou serve de escudo para reorganização do capitalismo mundial (“capitalismo verde”), o que pode ser verificado mediante as denominadas "cotas de carbono", o fato de que os países desenvolvidos despejam seu lixo nos países subdesenvolvidos para maquiar a quantidade de lixo tóxico e doméstico produzido, que é simplesmente escoado às nações pobres.

De fato, não se pode utilizar o DS como mantenedor do status quo; em verdade, deve ser analisado de forma cautelosa e crítica, já que pode favorecer e fortalecer ainda mais o antropocentrismo e, por via de corolário, o capitalismo. Oportuno frisar, ainda, o evidente equívoco de se enxergar a crise ecológica como uma crise de consciência, visto que tal atitude visa a mudanças apenas cosméticas.

A proposta do DS teve a vantagem de denunciar como inviáveis os atuais modelos de desenvolvimento, tanto no hemisfério Norte como no Sul, que segue padrões de crescimento econômico não sustentáveis em longo prazo. Prevê que o crescimento econômico não pode ocorrer sem a superação da pobreza e o respeito aos limites ecológicos. Segundo Escobar, são 
quatro os pilares básicos do conceito: preservação da natureza; eliminação da pobreza; crescimento econômico; garantia de existência das gerações futuras; concebidos em conjunto, conferem a possibilidade de alcançar uma sustentabilidade que seja global (MAIA, 2015, p. $44)$.

Três são as correntes qualificativas para o desenvolvimento ambiental, de acordo com Escobar (apud MAIA, 2015, p. 45):

\begin{abstract}
Liberal: que pretende apenas atribuir taxas, impostos ou bônus ao direito de poluir ou utilizar os recursos naturais; Culturalista: que defende a mudança do modelo de desenvolvimento atual e a estruturação de um novo sistema, baseado em conteúdos culturais para a promoção do homem; Ecossocialista: que advoga que a defesa da sustentabilidade da natureza é basicamente ideológica e, por trás dela, encontra-se a defesa da sustentabilidade do capital, criticando as políticas do grande Capital e defendendo uma maior intervenção estatal na economia.
\end{abstract}

Dos movimentos acima nominados, oportuno discorrer acerca do ecossocialismo, que alia ecologia política com marxismo, cujo fundamento se dá a partir das necessidades de se articular as lutas das classes subalternas àquelas que se referem à defesa do ambiente. Para Löwy (2005, p. 47), "trata-se de uma corrente de pensamento e de ação ecológica que faz suas as aquisições fundamentais do marxismo - ao mesmo tempo em que o livra das suas escórias produtivistas", englobando "as teorias e os movimentos que aspiram a subordinar o valor de troca ao valor de uso, organizando a produção em função das necessidades sociais e das exigências da proteção do meio ambiente" (LÖWY, 2005, p. 49).

Com base nessa concepção, sustenta Löwy ser necessária a construção de uma ética ecossocialista, fundada sob valores humanos qualitativos, na contramão da máquina de quantificação do capital, cuja lógica é estruturalmente incompatível com critérios éticos. Para ele (2005, p. 67), uma ética ecossocialista deveria buscar uma revalorização daqueles valores éticos já encontrados nas lutas camponesas e populares contra a mercantilização capitalista na Inglaterra do século XVIII, tendo principal fundamento a ética social (assentada na necessidade da construção de um novo paradigma de produção e distribuição), de uma ética igualitária (baseada na apropriação coletiva dos meios de produção e na distribuição dos bens e serviços de acordo com as necessidades socialmente estabelecidas), de uma ética democrática (consubstanciada pela socialização democrática das forças produtivas), de uma ética responsável (para com a manutenção da espécie humana e da humanidade enquanto tal). 
Por derradeiro, de uma ética radical, voltada para a luta radical por um novo modelo de civilização (LÖWY, 2005, p. 76).

O que se pode retirar de extremamente positivo dessa corrente é que ela tem a capacidade de refutar o modo de acumulação capitalista/moderna, trazendo à tona os elementos mais expressivos da crise da civilização tecnológica; nesse passo, Löwy (1995, p. 255) alude que "o movimento ecológico constitui, neste final de século XX, a mais importante forma de renovação da crítica romântica contra a civilização industrial moderna".

Com efeito, é desse espírito crítico que se necessita estar imbuído para se tentar perquirir as raízes da crise ecológica, que encontra seu principal fundamento na forma de produção do capital, no intuito de superar a dicotomia existente entre sujeito e objeto (ser humano e natureza), consistente em um dos principais desafios da atualidade e uma das características fundamentais da civilização capitalista.

\section{CONCLUSÃO}

Conforme se buscou demonstrar pelo presente artigo, urge combater a visão de desenvolvimento sustentável (DS) segundo a qual primeiro se desenvolve para só depois se preocupar em sustentar; como visto, o conceito em questão pode ser apropriado por diversos atores e grupos de interesse, por isso a necessidade de se debater a sua real finalidade e a melhor visão que deve ser dada em relação a ele.

Observou-se ao longo do artigo a tendência de apropriação corporativo-empresarial do DS, em virtude de uma histórica dificuldade metodológica na aplicabilidade desse conceito para salvaguarda do ambiente, bem como na formulação de uma técnica jurídico-ambiental capaz de perceber e incorporar as diferentes dimensões de sustentabilidade na sua elaboração e aplicação.

Diante de tais constatações, restou demonstrado que - muitas vezes - as estratégias de apropriação dos recursos naturais dos países em desenvolvimento e subdesenvolvidos, na perspectiva da globalização econômica, legitimam seus discursos na retórica do desenvolvimento sustentável. Por isso, foram mencionados os conceitos de desenvolvimento como liberdade e o desenvolvimento includente, como propostas capazes de amenizar a desigualdade que o "mau desenvolvimento" pode gerar, de maneira que se busquem objetivos sociais e éticos. 
Consoante se infere pelo explicitado em linhas anteriores, o conceito de DS é mais representativo do ideário das classes dominantes, por conservar os lucros e evitar a mudança de hábitos quase sem alterar o rumo, cabendo, assim, sua problematização e superação. Já o ideal de sustentabilidade se trata de um aspecto mais geral, definindo-o como complexo, instigante e desafiador, já que trouxe um conceito biológico para a política e economia admitindo o contexto ecológico como uma condição objetiva de qualquer atividade social. Em razão disso, faz-se necessário reconhecer a problemática em questão sob o enfoque da sustentabilidade, conceito mais amplo e que consiste em um ideal que transcende ao referido conceito de DS.

Imperioso, portanto, avaliar com certo cuidado o mencionado conceito, sem perder de vista a relevância que ele representa, mas sempre com o espírito crítico de que se necessita estar imbuído para se tentar perquirir as raízes da crise ecológica e suas formas de enfrentamento, sempre evitando uma postura apática e acomodativa do mercado, que é mantenedora do status quo. Pressupõe-se, assim, esse tipo de pensamento crítico como premissa básica para se alcançar uma perspectiva social e ecológica sustentável.

Por fim, foram analisadas três correntes qualificativas para o desenvolvimento ambiental: a liberal, a culturalista e a ecossocialista, tendo se demonstrado que o principal aspecto positivo dessa última (o ecossocialismo) é ter como objetivo refutar o modo de acumulação capitalista/moderna, trazendo à tona os elementos mais expressivos da crise da civilização tecnológica e, com isso, enfrentar os principais desafios da atualidade, a fim de se alcançar uma perspectiva social e ecológica sustentável.

\section{REFERÊNCIAS}

ALBUQUERQUE, J. de L. Gestão ambiental e responsabilidade social: conceitos, ferramentas e aplicações. São Paulo: Atlas, 2009.

CAMPOS JUNIOR, A. da S. Biodireito e Desenvolvimento Sustentável. Revista de Informação Legislativa. Brasília a. 49 n. 196 out./dez. 2012.

FREITAS, J. Sustentabilidade: direito ao futuro.2. ed. Belo Horizonte: Fórum, 2012.

GADOTTI, M. A terra é a casa do homem. Revista Educação, São Paulo: Segmento, abr. 
1999.

JACOBI, P. Educação ambiental, cidadania e sustentabilidade. Cadernos de Pesquisa, São Paulo, n. 118, março/ 2003. Disponível em: $<$ http://www.scielo.br/scielo.php?script=sci_arttext\&pid=S010015742003000100008\&lng=en\&nrm=iso>. Acesso em: 21 fev. 2020.

JAQUES, A. da S.; SILVEIRA, V. O. da. O direito tributário como instrumento eficaz na busca do desenvolvimento (ambiental) sustentável. XXVIII Conselho Nacional de Pesquisa e Pós-graduação em Direito (CONPEDI - Goiânia), 2019. Disponível em: http://conpedi.danilolr.info/publicacoes/no85g2cd/1jj4cy28/QiL6jwIa3vX3J1I1.pdf . Acesso em 22 abr. 2020.

LATOUCHE, S. Pequeno Tratado do Decrescimento Sereno. São Paulo: Martins Fontes, 2009.

LEFF, E. Saber ambiental: sustentabilidade, racionalidade, complexidade, poder. Petrópolis, RJ: Vozes, 2001.

LOUREIRO, C. F. B. Sustentabilidade e Educação: um olhar da ecologia política. São Paulo: Cortez, 2012.

LÖWY, M. Ecologia e socialismo. São Paulo: Cortez, 2005.

LÖWY, M.; SAYRE, R. Revolta e melancolia: O romantismo na contramão da modernidade. Rio de Janeiro: Vozes, 1995.

MACHADO, P. A. L. Direito Ambiental Brasileiro. 21. ed. São Paulo: Malheiros, 2013.

MACHADO, P. A. L. Meio ambiente e Constituição Federal (LGL1988\3). Interesse Público, ano 5, n. 21, set.-out. 2003.

MAIA, J. S. da S. Educação Ambiental Crítica e Formação de Professores. 1 ed. Curitiba: Appris, 2015.

MARQUES, C. Quando o futuro se torna o presente da crise ambiental. A jurisprudência.... Revista de Direito da Cidade, [S.1.], v. 8, n. 2, p. 704-728, abr. 2016. ISSN 2317-7721. Disponível em: 〈http://www.e-publicacoes.uerj.br/index.php/rdc/article/view/22367>. Acesso 
em: 16 mar. 2020. doi:https://doi.org/10.12957/rdc.2016.22367

MILARÉ, E. Direito do ambiente: a gestão ambiental em foco: doutrina, jurisprudência, glossário. 6. ed. rev., atual. e ampl. São Paulo: Revista dos Tribunais, 2009.

ORGANIZAÇÃO das Nações Unidas (ONU). Declaração da Conferência de ONU no Ambiente Humano, Estocolmo, 5-16 de junho de 1972.

ORGANIZAÇÃO das Nações Unidas (ONU). Relatório Brundtland: "Nosso Futuro Comum". 1987.

PADILHA, N. S. Fundamentos constitucionais do Direito Ambiental brasileiro. Rio de Janeiro: Elsevier, 2010.

SAMPAIO, J. A. L. Constituição e meio ambiente na perspectiva do direito constitucional comparado. In: SAMPAIO, J. A. L.; WOLD, C.; NARDY, A. Princípios de Direito Ambiental na dimensão internacional e comparada. Belo Horizonte: Del Rey, 2003.

SARTORI, S.; LATRÔNICO, F.; CAMPOS, L. M. S. Sustentabilidade e desenvolvimento sustentável: Uma taxonomia no campo da literatura. Revista Ambiente \& Sociedade, v. 17, n. 1, p. 1-22, 2014.

TYBUSCH, J. S. Ecologia Política, Sustentabilidade e Direito. In Sustentabilidade multidimensional [tese de Doutorado]: elementos reflexivos na produção da técnica jurídicoambiental / Jerônimo Siqueira Tybusch; orientador, João Eduardo Pinto Bastos Lupi. Florianópolis, SC, 2011. 